\title{
Intake of dietary fiber as a putative prevention of colorectal cancer in Pakistan.
}

\author{
Laila Tul Qadar*, Faryal Tahir, Syeda Zubaria Qamar, Sayed Mustafa Mahmood Shah
}

Department of Internal Medicine, Dow University of Health Sciences, Baba-e-Urdu Road Karachi, Pakistan

Colorectal cancer (CRC) is an unchecked proliferation of abnormal cells that initiates in the colon or rectum. Most of them start as small growths termed adenomatous polyps causing alteration in the layers of colon, spreading to nearby lymph nodes and distant parts of the body. Its incidence is increasingly reported in younger population i.e. less than 40 years of age. In Pakistan, it is concerned that an aging population over the coming decade and changing lifestyle patterns may lead to a higher incidence of CRC [1]. Risk factors of colorectal carcinoma are enumerated as older age, inherited gene mutations, inflammatory intestinal conditions, diabetes, smoking, alcohol intake, low fiber and high fat diet and sedentary life style [2]. Bleeding per rectum and anaemia are high risk clinical features for CRC.

CRC is the most preventable form of cancer. It is suggested that individuals who consume highest intakes of dietary fibre, particularly cereals and fruits, bear reduced risks of incident colorectal adenoma and cancer of distal colon and that this beneficial effect of dietary fibre may begin early in colorectal carcinogenesis. Furthermore, the US Food and Drug Administration have approved health claims supporting the effect of dietary fibre in cancer prevention [3]. The mechanisms by which dietary fibres can prevent colorectal carcinoma include formation of short chain fatty acids in the colon where they promote healthy composition of gut microbiota and exert their anticancer properties [4]. Also, dietary fibre increases fecal bulk and viscosity, minimizes the time for proteolytic fermentation and shortens the contact between mucosal cells and the potential carcinogens. Moreover, dietary fibre can lower fecal $\mathrm{pH}$ in the colon and bind/excrete potential luminal carcinogens like secondary bile acids thus, providing a healthy intestinal environment [5].

CRC is known as a disease of the Western World. Pakistan belongs to the developing countries, so the incidence appears to be low. But due to the adoption of Western life style including dietary practices like fast food consumption that is low in fibre and rich in fats, incidence of colorectal cancer in developing countries is rising, including Pakistan. According to a study conducted on Pakistani society, it is found that people prefer fast food over home cooked food due to better taste and ready availability, particularly at their work place due to their busy schedules [6].

According to our knowledge, this might be the first local editorial highlighting the inclusion of dietary fiber to downshift the up going statistics of colorectal carcinoma in Pakistan. It is recommended that dietary awareness programs should be arranged at national and local levels, with the involvement of our physician workforce to screen patients at high-risk. Pakistan currently lacks formal screening guidelines for colorectal carcinoma, and provision of screening facilities is sporadically distributed across the country. It is therefore imperative to carefully assess our local CRC disease burden and its projected rise in the future. We hope that no more innocent lives are lost just because a basic fundamental right was not provided at the right time. As previous research on prostate, lung, colorectal, and ovarian cancer screening trial discovered that individuals with highest intake of fiber had a $27 \%$ reduced risk of prevalent adenoma [7]. Now is the need of enabling the health care professionals to map out and improve strategies for primary prevention of CRC.

KEYWORDS: Colorectal cancer, Dietary fiber, Pakistan.

Accepted on December 13, 2018

\section{References}

1. Amini AQ, Samo KA, Memon AS. Colorectal cancer in younger population: our experience. J Pak Med Assoc. 2013;63(10):1275-7.

2. Bhurgri $\mathrm{Y}$, Khan $\mathrm{T}$, Kayani $\mathrm{N}$, et al. Incidence and current trends of colorectal malignancies in an unscreened, low risk Pakistan population. Asian Pac J Cancer Prev. 2011;12(3):703-8.
3. Kunzmann AT, Coleman HG, Huang W-Y, et al. Dietary fiber intake and risk of colorectal cancer and incident and recurrent adenoma in the Prostate, Lung, Colorectal, and Ovarian Cancer Screening Trial. Am J Clin Nutr. 2015;102(4):881-90.

4. Code of Federal Regulations Title 21. Health claims: fibercontaining grain products, fruits, and vegetables and cancer. (2010). 
5. Zeng H, Lazarova DL, Bordonaro M. Mechanisms linking dietary fiber, gut microbiota and colon cancer prevention. World J Gastrointest Oncol. 2014;6(2):41-51.

6. Yahya F, Zafar R, Shafiq S. Trend of fast food consumption and its effect on Pakistani society. Food Science and Quality Management. (2013);(11):1-8

7. Peters U, Sinha R, Chatterjee N, et al. Dietary fibre and colorectal adenoma in a colorectal cancer early detection programme. Lancet. 2003;(361):1491-5.

\section{*Correspondence to:}

Laila Tul Qadar

Department of Internal Medicine,

Dow University of Health Sciences,

Baba-e-Urdu Road Karachi, Pakistan

Tel: +92 3432360320

E-mail: lailarahman1997@hotmail.com 